\title{
Effect of Camphor on the Behavior of Leukocytes In vitro and In vivo in Acute Inflammatory Response
}

\author{
Saulo Euclides Silva-Filho, Francielli Maria de Souza Silva-Comar, Luiz \\ Alexandre Marques Wiirzler, Rilson José do Pinho, Renata Grespan, Ciomar \\ Aparecida Bersani-Amado and Roberto Kenji Nakamura Cuman*
}

Laboratory of Inflammation, Department of Pharmacology and Therapeutics, State University of Maringá, Maringá, PR, Brazil

*For correspondence: Email: rkncuman@uem.br; Tel: +55 44 3011-4867

Received: 12 May 2014

Revised accepted: 26 October 2014

\begin{abstract}
Purpose: To evaluate the effect of camphor on acute inflammatory response by leukocytes on chemotaxis, antiedematogenic and phagocytic activities.

Methods: The effect of camphor in acute inflammatory response evaluated by neutrophil chemotaxis, ear edema induced by croton oil, activity of the enzyme myeloperoxidase (MPO) and phagocytic activity of macrophages in Swiss mice.

Results: Camphor treatment did not show any cytotoxicity. Camphor at 3, 10, and $30 \mu \mathrm{g} / \mathrm{ml}$ doses exhibited significant $(p<0.01)$ reduction on leukocyte migration toward $N$-formyl methionyl leucyl phenylalanine fMLP. Topical treatment with camphor did not reduce significant ear edema or MPO activity at any of the doses tested. However, in contrast, oral treatment with 100 and $200 \mathrm{mg} / \mathrm{kg}$ camphor significantly $(p<0.01)$ reduced ear edema and myeloperoxidase (MPO) activity. Additionally, the phagocytic activity of macrophages was not affected by camphor.

Conclusions: These results indicate that the anti-inflammatory activity of camphor may be related to the inhibition of leukocyte migration and antiedematogenic activity.
\end{abstract}

Keywords: Camphor, Inflammatory response, Chemotaxis, Macrophages, Phagocytic, Leukocytes, Edema

Tropical Journal of Pharmaceutical Research is indexed by Science Citation Index (SciSearch), Scopus, International Pharmaceutical Abstract, Chemical Abstracts, Embase, Index Copernicus, EBSCO, African Index Medicus, JournalSeek, Journal Citation Reports/Science Edition, Directory of Open Access Journals (DOAJ), African Journal Online, Bioline International, Open-J-Gate and Pharmacy Abstracts

\section{INTRODUCTION}

Acute inflammation is characterized by swelling, heat, redness, and pain and is an important defense mechanism against invading pathogens. The mediators that arise from the cyclooxygenase (COX) cascade and role of biologically active prostaglandins in the inflammatory process and body homoeostasis have been extensively studied. Cyclooxygenase inhibitors prevent prostaglandin biosynthesis and are effective anti-inflammatory compounds that reduce the levels of prostaglandins and cardinal signs of inflammation. Neutrophil chemotaxis to sites of inflammation is an essential process during normal immune responses to tissue injury and infection. Phagocytes form an important front-line defense against infection and are a major part of innate immunity and the process of removing pathogens from the blood and tissue fluids [1].

Anti-inflammatory drugs, such as steroids and nonsteroidal anti-inflammatory drugs, cause adverse effects, including gastric damage. The use of these drugs for their anti-inflammatory 
effects has not been successful in all cases. Hence, the search for natural products has increased.

Camphor $\left(\mathrm{C}_{10} \mathrm{H}_{16} \mathrm{O}\right)$ is a natural and synthetic terpenoid ketone compound that is present in Cinnamomum camphora and other plant species [2]. It is a popular household remedy that is believed to act as an aphrodisiac, contraceptive, abortifacient, and lactation suppressor [3]. Camphor has been used topically to relieve pain and treat warts, cold sores, hemorrhoids, and osteoarthritis. It is a common ingredient in a wide variety of over-the-counter topical products [4]. The human lethal dose has been reported to be $50-500 \mathrm{mg} / \mathrm{kg}$ [3]. However, the toxicity of camphor in rats is not considered to be high, with an $L_{50}$ of $3000 \mathrm{mg} / \mathrm{kg}$ [5].

Several studies have been performed with extracts of plants that contain camphor, demonstrating anti-inflammatory, antioxidative, and antimicrobial effects [6,7]. However, very few studies have specifically evaluated the effects of camphor on the acute inflammatory response, hence the need for this study.

\section{EXPERIMENTAL}

\section{Chemicals}

Camphor, Dexamethasone, Zymosan, LPS (lipopolysaccharides from Salmonella enterica serotype typhimurium), fMLP (N-formyl methionyl leucyl phenylalanine) and Cróton oil were purchased from Sigma-Aldrich (St. Louis, MO, USA).

\section{Animals}

Male Swiss mice, weighing 25 - $30 \mathrm{~g}$, were provided by the Central Animal House of the State University of Maringá, Maringá, Brazil. The animals were housed at $22 \pm 2{ }^{\circ} \mathrm{C}$ under a $12 / 12$ h light/dark cycle. Prior to the experiments, the animals were fasted overnight, with water provided ad libitum. The experimental protocols were approved by the Ethical Committee on Animal Experimentation of the State University of Maringá (CEAE/UEM 070/2012). The animals were handled according to the standard protocols for the use of laboratory animals [8].

\section{Cell viability analysis}

The MTT (3-[4,5-dimethylthiazol-2-yl]-2,5diphenyl-2H-tetrazolium bromide; Sigma) assay is based on the mitochondrial enzyme reduction of tetrazolium dye to detect and determine cell viability. Neutrophils were obtained from the peritoneal cavity of mice $4 \mathrm{~h}$ after zymosan injection ( $1 \mathrm{mg} /$ cavity, i.p.). Briefly, the cells were plated at a density of $5 \times 10^{5}$ cells/well in a volume of $100 \mu \mathrm{l}$ RPMI 1640 medium supplemented with $10 \%$ fetal bovine serum (FBS) and $100 \mathrm{U} / \mathrm{ml}$ penicillin + $100 \mu \mathrm{g} / \mathrm{ml}$ streptomycin in 96-well plates. The cells were incubated with varying concentrations of camphor $(3,10,30$, and $90 \mu \mathrm{g} / \mathrm{ml})$ at $37^{\circ} \mathrm{C}$ in 5 $\% \mathrm{CO}_{2}$ for $90 \mathrm{~min}$ followed by the addition of 10 $\mu \mathrm{l}$ MTT $(5 \mathrm{mg} / \mathrm{ml})$ stock solution to each well. After $2 \mathrm{~h}$ of incubation at $37{ }^{\circ} \mathrm{C}, 150 \mu \mathrm{l}$ of the supernatant was removed, and $100 \mu$ dimethyl sulfoxide (DMSO) was added to each well. The cells were incubated at $25{ }^{\circ} \mathrm{C}$ for a further 10 min, and absorbance was measured using a Biochrom Asys Expert plus microplate reader at a wavelength of $540 \mathrm{~nm}$. The values of the blank wells were subtracted from each well of treated and control cells. Viability was determined using Eq 1.

Viability $(\%)=\{(A t-A b) /(A c-A b)\} 100 \ldots \ldots(1)$

where At, $A b$ and $A c$ are the absorbance of treated cells, blank and control, respectively

\section{Evaluation of in vitro neutrophil chemotaxis}

To evaluate the effect of camphor on chemotaxis, neutrophils were obtained from the peritoneal cavity of mice by peritoneal wasing with $3 \mathrm{ml}$ of phosphate-buffered saline (PBS) that contained ethylene-diaminetetraacetic acid (EDTA) $4 \mathrm{~h}$ after zymosan injection $(1 \mathrm{mg} /$ cavity, i.p.). The cell suspension was centrifuged at $1000 \mathrm{rpm}$ for $10 \mathrm{~min}$ at $4{ }^{\circ} \mathrm{C}$ and resuspended in RPMI1640 medium [9]. The cell number was adjusted to $1 \times 10^{6}$ cells/ml in RPMI 1640 medium that contained $0.1 \%$ bovine serum albumin (BSA). A chemotaxis assay was performed using a 48-well microchemotaxis plate (Neuro Probe), in which the chambers were separated by a polyvinylpyrrolidone-free polycarbonate membrane (5 $\mu \mathrm{m}$ pore size). The chemoattractant, $\mathrm{N}$-formyl methionyl leucyl phenylalanine (fMLP; $10^{-6} \mathrm{M}$ ), and vehicle (RPMI 1640) were placed in the lower chamber. A neutrophil suspension $\left(1 \times 10^{6} \mathrm{cells} / \mathrm{ml}\right)$ was pretreated for $30 \mathrm{~min}$ with camphor $(1,3,10,30$, 60 , and $90 \mu \mathrm{g} / \mathrm{ml}$ ) and then placed in the upper chamber. The chambers were incubated at $37^{\circ} \mathrm{C}$ with $5 \% \mathrm{CO}_{2}$ for $1 \mathrm{~h}$. Following incubation, the membrane was washed in phosphate-buffered saline (PBS), fixed in methanol, and stained with Instant Prov. The membrane area of each well was scored using light microscopy to count the cells present in five random fields. The results are expressed as the mean number of 
neutrophils per field and are representative of triplicate measurements from three separate experiments.

\section{Evaluation of camphor in topical ear edema inflammation model}

Cutaneous inflammation was induced by the application of $5 \%$ croton oil $(10 \mu \mathrm{l})$ in acetone (vehicle) in the inner surface of the mouse right ear [9]. The left ear received an equal volume of vehicle. Camphor $(0.5,1,2.5$, and $5 \mathrm{mg} / \mathrm{ear})$, dexamethasone (0.1 mg/ear, anti-inflammatory drug reference), or vehicle was applied topically to the right ear $1 \mathrm{~h}$ before croton oil application. The effect of oral camphor treatment was also studied. For oral treatment, the mice received camphor $(100,200$, or $400 \mathrm{mg} / \mathrm{kg})$ or dexamethasone $(1 \mathrm{mg} / \mathrm{kg}$, anti-inflammatory drug reference), diluted in hydroalcoholic vehicle that contained $2 \%$ ethyl alcohol and $1 \%$ Tween. Four hours after application of the inflammatory stimulus, the mice were euthanized with an anaesthetic overdose of ketamine/xylazine [10], and a $7 \mathrm{~mm}$ diameter plug was removed from both the treated and untreated ears. Edema was measured as the weight difference between the two plugs. The data are expressed as the mean \pm SEM weight of the ears.

\section{Determination of myeloperoxidase activity}

Myeloperoxidase (MPO) activity was assayed using homogenate supernatants of the ear sections (i.e., untreated controls and animals treated with camphor or dexamethasone) [9]. The ear sections were placed in $50 \mathrm{mM}$ potassium phosphate buffer $(\mathrm{pH}$ 6.0) that contained $0.5 \%$ hexadecyl trimethyl ammonium bromide (1 ml/50 mg of tissue; Sigma) in a Potter homogenizer. The homogenate was shaken in a vortex mixer and centrifuged for $5 \mathrm{~min}$, and $10 \mu \mathrm{l}$ of the supernatant was added to each well of a 96-well microplate in triplicate. Two hundred microliters of the buffer solution that contained $16.7 \mathrm{mg}$ o-dianisidine dihydrochloride (Sigma), $90 \mathrm{ml}$ double-distilled water, $10 \mathrm{ml}$ potassium phosphate buffer, and $50 \mu \mathrm{l}$ of $1 \% \mathrm{H}_{2} \mathrm{O}_{2}$ were added. The enzyme reaction was stopped by the addition of sodium acetate. Enzyme activity was determined by absorbance measured at $460 \mathrm{~nm}$ using a microplate spectrophotometer (Spectra Max Plus).

Peritoneal macrophage preparation and determination of phagocytosis activity

To evaluate the effect of camphor on phagocytosis activity, macrophages were obtained from the peritoneal cavity of the mice.
To collect the macrophages, the animals were euthanized, and $5 \mathrm{ml}$ PBS was injected intraperitoneally. Phosphate-buffered saline that contained peritoneal exudate cells was recollected and kept on ice. The suspended cells were centrifuged at 1500 rotations per minute for $10 \mathrm{~min}$ and resuspended with complete RPMI1640. Peritoneal exudate cells were then isolated on 24-well culture plates and allowed to adhere for $1 \mathrm{~h}$ at $37{ }^{\circ} \mathrm{C}$ in $5 \% \mathrm{CO}_{2}$. After nonadherent cells were removed, the remaining adherent cells were designated as peritoneal macrophages. Cell viability, evaluated by the exclusion test with Trypan blue, was $\geq 90 \%$ in all of the experiments. The cells were incubated for $24 \mathrm{~h}$ at $37{ }^{\circ} \mathrm{C}$ in $5 \% \mathrm{CO}_{2}$ with different concentrations of camphor $(3,10,30$, or $90 \mu \mathrm{g} / \mathrm{ml})$ in complete RPMI-1640 medium. Lipopolysaccharide (LPS; $20 \mu \mathrm{g} / \mathrm{ml}$ ) was used as a positive control, and RPMI-1640 medium was used as a negative control. After incubation, $100 \mu \mathrm{l}$ of a $3 \%$ suspension of chicken red blood cells (CRBCs) was added to each well. CRBCs were used to assess macrophage phagocytosis. After $1 \mathrm{~h}$, the macrophages were fixed and stained. Phagocytosis index was measured by counting the number of phagocytosed CRBCs per 100 macrophages [11].

\section{Statistical analysis}

The data are expressed as mean \pm SEM for each experimental group. The results were statistically analyzed using one-way analysis of variance (ANOVA) followed by Tukey's test. The software used was GraphPad Prism version 5.01, GrahPad Software, Inc. Differences were considered significant at $p<0.05$.

\section{RESULTS}

\section{Cell viability}

In the cell viability assay, camphor was tested at different concentrations. Concentrations of 3,10 , 30 , and $90 \mu \mathrm{g} / \mathrm{ml}$ presented cell viability of 82.5 , $76,85.8$, and $88 \%$, respectively, indicating that camphor did not induce cell death when compared with the untreated cells.

\section{Effect of camphor on in vitro neutrophil chemotaxis}

To investigate the direct effect of camphor on leukocyte chemotaxis, different concentrations of camphor were tested $(1,3,10,30,60$, and 90 $\mu \mathrm{g} / \mathrm{ml}$ ) in the in vitro chemotaxis assay. fMLP was the chemotactic agent used to promote migration of neutrophils. The results obtained are 
shown in Figure 1. MLP induced significant leukocyte migration compared to the vehicle (RPMI1640). Camphor at doses of 3, 10, and 30 $\mu \mathrm{g} / \mathrm{ml}$ significantly reduced $(p<0.01)$ neutrophil migration toward fMLP $\left(10^{-6} \mathrm{M} ; 25.09 \pm 0.89\right.$, $36.42 \pm 1.07$, and $23.53 \pm 2.18 \%$, respectively), as illustrated in Figure 1.

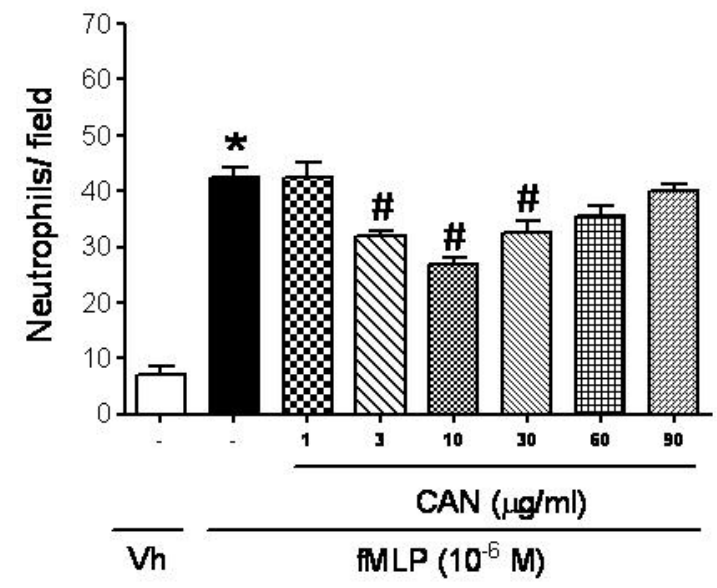

Figure 1: Effect of camphor on in vitro leukocyte chemotaxis. Leukocytes were obtained from zymosaninduced peritonitis (200 $\mu \mathrm{g} /$ cavity) and stimulated with fMLP $\left(10^{-6}\right)$ after 30 min of CAM treatments at doses of $1,3,10,30,60$ and $90 \mu \mathrm{g} / \mathrm{mL}$. Values are mean \pm S.E.M. $(n=5)$ and are representative of three independent experiments. ${ }^{*} p<0.05$ versus $\mathrm{Vh}$ (vehicle), ${ }^{\#} p<0.05$ versus group of leukocytes stimulated with fMLP

\section{Effect of camphor on the ear edema and MPO activity}

Topical croton oil application in the right ear of mice induced an evident inflammatory response $4 \mathrm{~h}$ later, promoting ear edema formation. Topical camphor treatment did not reduce ear edema at any of the doses tested. In contrast, topical administration of dexamethasone as a reference drug significantly reduced ear edema by $59.6 \%(p<0.01$; Figure $2 \mathrm{~A})$. Topically administered camphor did not reduce MPO activity at any of the doses tested, whereas dexamethasone inhibited MPO activity by 61.32 $\%(p<0.05$; Figure 2B). When camphor was administered orally by gavage, a reduction of ear edema was observed. Camphor treatment at doses of 100 and $200 \mathrm{mg} / \mathrm{kg}$ significantly reduced the intensity of edema by 59.4 and 49.8 $\%$, respectively $(p<0.01)$, similar to the $64.3 \%$ reduction induced by dexamethasone $(1 \mathrm{mg} / \mathrm{kg}$; $p<0.01)$. Camphor at a dose of $400 \mathrm{mg} / \mathrm{kg}$ increased ear edema by $21 \%$ (Figure 2C).
Additionally, the results demonstrated that oral treatment with camphor significantly reduced MPO activity by 51.5 and $60.6 \%$ at doses of 100 and $200 \mathrm{mg} / \mathrm{kg}$, respectively $(p<0.01)$, dexamethasone $(1 \mathrm{mg} / \mathrm{kg})$ significantly inhibited MPO activity by $57.6 \%(p<0.01)$. Camphor, at a dose of $400 \mathrm{mg} / \mathrm{kg}$, increased MPO activity by 21 $\%$ (Figure 2D).

\section{Effect of camphor on the phagocytic activity of macrophages}

Camphor did not exert any influence on the phagocytic activity of macrophages (Figure 3).

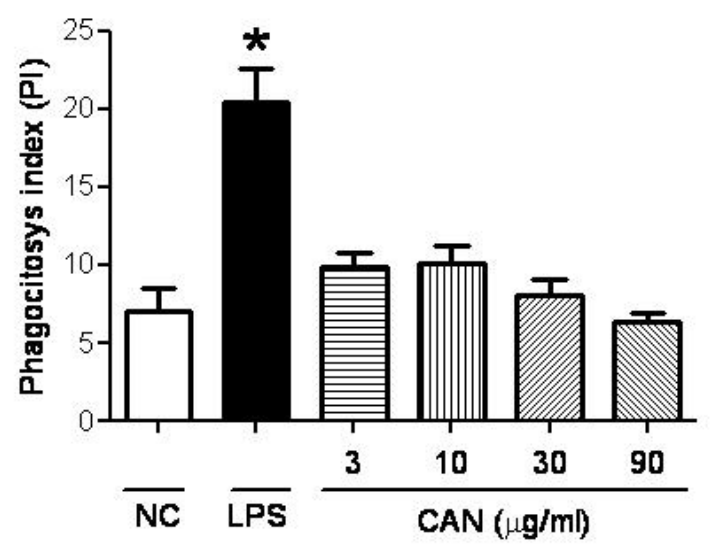

Figure 3: Effect of CAN on phagocytosis of macrophages. Macrophages were obtained from the peritoneal cavity of mice and treated with different doses of CAN $(3,10,30$ and $90 \mu \mathrm{g} / \mathrm{ml})$. LPS at 20 $\mu \mathrm{g} / \mathrm{ml}$ was used as positive control. ${ }^{*} p<0.05$ versus $\mathrm{NC}$ (negative control), $\# p<0.05$, compared to the NC (ANOVA, Tukey's test)

\section{DISCUSSION}

Polymorphonuclear leukocyte recruitment is known to be an essential factor in the acute inflammatory process by acting as first-line defense cells in the initiation and resolution phases of this process, involving the participation of many inflammatory mediators, such as prostanoids.

In vitro treatment with camphor did not affect the viability of neutrophils at any of the concentrations tested, indicating that the direct effect of camphor on leukocyte chemotaxis inhibition did not occur because of toxic effects that induce cell death.

Studies performed with extracts and essential oils of Artemisia fukudo and Cinnamomum camphora that contain camphor as a major constituent found that they inhibited 
A

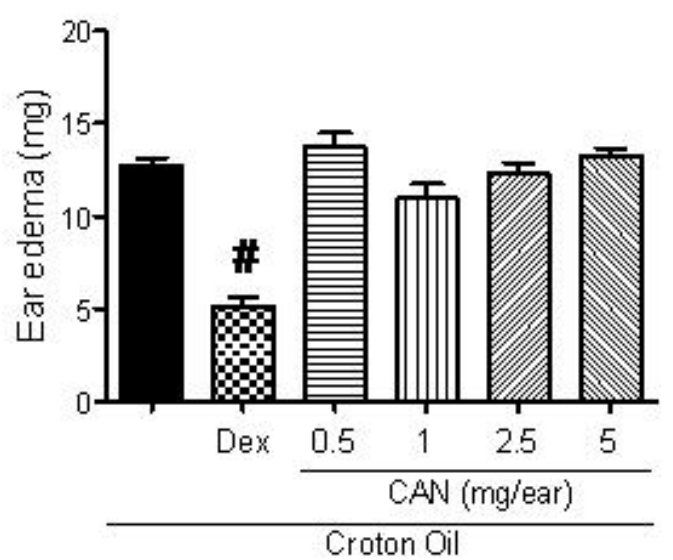

$\mathrm{C}$

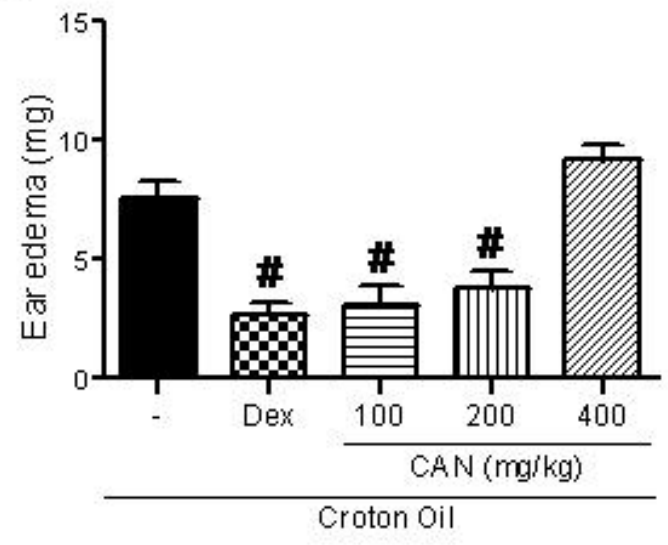

B

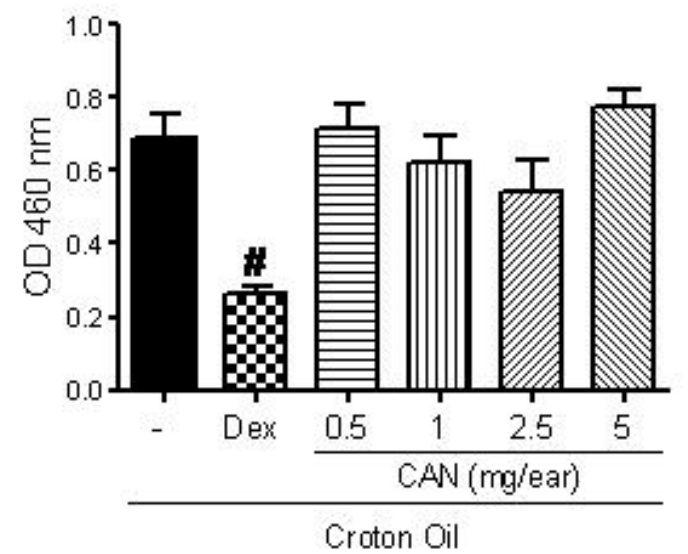

D

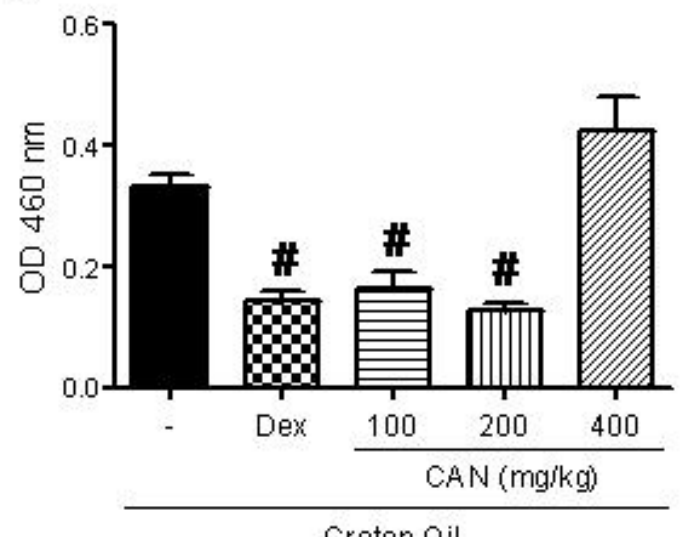

Figure 2: Effect of Camphor on the ear edema and myeloperoxidase activity. Effect of topical treatment with camphor on ear edema (A) and myeloperoxidase activity (MPO) (B) induced by croton oil in ear tissues from mice. The animals were treated topically with camphor or dexamethasone (Dex) $1 \mathrm{~h}$ before croton oil application (10 $\mu / /$ ear). Effect of oral treatment with camphor on ear edema (C) and MPO activity (D) induced by croton oil in ear tissues from mice. The animals were treated oral with camphor or Dex $1 \mathrm{~h}$ before croton oil application (10 $\mu l /$ ear). Dex was used as anti-inflammatory drug (positive control). The right ears received only the vehicle (Basal). Ear edema and MPO activity were determined 4 hours after application of croton oil. Data are mean \pm S.E.M., ${ }^{\#} p<0.05$, compared to the control group (croton oil) (ANOVA, Tukey's test)

proinflammatory cytokines, such as interleukin$1 \beta$ (IL-1 $\beta$ ), interleukin-6 (IL-6), tumor necrosis factor- $\alpha$ (TNF- $\alpha$ ), and prostaglandin E2 (PGE2) in macrophage cultures $[13,14]$. Indeed, camphor as an isolated compound inhibited the production of IL-1 $\beta, I L-4$, and TNF- $\alpha$ [12]. Our data suggest that camphor may act by inhibiting proinflammatory cytokines induced by chemotactic agents. $\mathrm{fMLP}$ is a chemotactic agent involved in the release of many cytokines upon binding to its G-protein-coupled receptor, activating multiple signaling cascades [13]. These pathways include the mitogen-activated protein kinase (MAPK) and phosphatidylinositol 3-kinase (PI-3K) cascades, which are important for the development of the functional responses of neutrophils in inflammation. Further studies should be performed to elucidate the anti-inflammatory mechanism of action of camphor.

To demonstrate the topical effect of camphor in vivo, we evaluated inflammatory ear edema induced by croton oil. This oil is an irritant that induces an inflammatory response by activating phospholipase A2 and initiating arachidonic acid metabolites [14], followed by COX-1- and COX2-induced prostaglandin production and 5lipoxygenase-induced leukotriene production. Prostaglandins and leukotrienes are inflammatory mediators involved in edema and leukocyte migration.

MPO enzyme is found in the azurophilic granules of neutrophils and other cells of myeloid origin. It 
catalyzes the production of hypochlorous acid (which has toxic effects on microorganism) from hydrogen peroxide and chloride, but it is harmful to tissue cells [15]. Myeloperoxidase is an indirect marker of neutrophil infiltration into tissue. Decreases in MPO activity suggest less neutrophil infiltration. Our data suggest that camphor exerts anti-inflammatory effects only when administered systemically. At higher doses (e.g., $400 \mathrm{mg} / \mathrm{kg}$ ), camphor has irritative effects. Oral dexamethasone administration inhibited phospholipase A2, consequently reducing eicosanoid production. Based on our results, we suggest that camphor inhibits chemotactic mediators that are released through different metabolic pathways. Our data showed that camphor effectively inhibited in vitro chemotaxis and leukocyte infiltration and had antiedematogenic activity when administered systemically.

Macrophages are phagocytic cells that play a central role in the immune response to inflammatory and infectious diseases. Lipopolysaccharide (LPS) is a major component of the outer membrane of Gram-negative bacteria and acts as one of the most powerful activators of resident macrophages by binding the CD14/toll-like receptor 4 (TLR-4)/MD2 receptor complex, leading to the activation of nuclear factor KB (NF-KB) and MAPKs, which not only promote the overproduction of cytokines, pro-inflammatory mediators, and phagocytosis but also induce the differentiation and maturation of monocytes/macrophages [16,17]. As an activator of macrophages, LPS is one of the most potent microbial initiators of inflammation, which can increase the secretion of $\mathrm{NO}$ in mouse peritoneal macrophages [16]. The stimulation of TLR-4 receptors by LPS results in a significant increase in the production of pro-inflammatory cytokines, such as IL-6 and TNF- $\alpha$ [18]. The rate and index of CRBC phagocytosis were positively correlated with the expression of TLR-4 [19].

$\mathrm{NO}$ is an inflammatory mediator secreted by macrophages that also increases macrophage activity $[16,20]$. Cinnamomum camphora and Ocotea odorifera extracts and their essential oils, which contain camphor, exhibit antioxidative activity [6], inhibiting free radical formation, such as NO and reactive oxygen species, and likely contributing to anti-inflammatory activity. Since camphor did not significantly alter the phagocytosis index at any of the concentrations tested, we suggest that camphor, as an isolated compound, is unlikely to be involved in the production of free radicals (e.g., NO) or pathways involved in the activation of TLR-4.

\section{CONCLUSION}

The results obtained show that camphor affects inflammatory response, inhibits neutrophil migration in vitro, has antiedematogenic activity, and decreases neutrophil infiltration in inflamed tissue. Camphor affects inflammatory response only after oral administration. It exerts antiinflammatory effects at low doses but has an irritant effect at higher doses. Further studies are needed to elucidate the mechanism of the action of camphor.

\section{ACKNOWLEDGEMENT}

This study was supported by CAPES (Coordenadoria de Aperfeiçoamento de Pessoal de Nível Superior) and $\mathrm{CNPq}$ (Conselho Nacional de Desenvolvimento Científico e Tecnológico), Brazil. The authors thank Mr. Jailson Araujo Dantas and Mrs. Celia Regina Miranda for technical assistance.

\section{REFERENCES}

1. Lehmann AK, Sornes S, Halstensen A. Phagocytosis: measurement by flow cytometry. J Immunol Methods 2000; 243: 229-242.

2. Siegel E, Wason S. Camphor Toxicity. Pediatr Clin North Am 1986; 33: 375-379

3. Liebelt EL, Shannon MW. Small doses, big problems: $A$ selected review of highly toxic common medications. Pediatr Emerg Care 1993; 9: 292-297.

4. Ragucci KR, Trangmar PR, Bigby JG, Detar TD. Camphor ingestion in a 10 year old male. South Med J 2007; 100: 204-207.

5. Yoneda JD, Leal, KZ, Seidl, PR, Azeredo, RBV, Kleinpeter, E. Cânfora: um bom modelo para ilustrar técnicas de RMN. Quím Nova 2007; 30: 2053-2056.

6. Lee HJ, Hyun EA, Yoon WJ, Kim BH, Rhee MH, Kang $H K$, Sho JY, Yoo ES. In vitro anti-inflammatory and anti-oxidative effects of Cinnamomum camphora extracts. J Ethnopharmacol 2006; 103: 208-216.

7. Yoon WJ, Moon JY, Song G, Lee YK, Han MS, Lee JS, Ihm BS, Lee WJ, Lee NH, Hyun CG Artemisia fukudo essential oil attenuates LPS-induced inflammation by suppressing NF-KB and MAPK activation in RAW 264.7 macropages. Food Chem Toxicol 2010; 48: 1222-1229.

8. National Institute os Health, USA. Public health service policy on human care and use of laboratory animals; 2002.

9. Fachini-Queiroz FC, Kummer $R$, Estêvão-Silva CF, Carvalho MDB, Cunha JM, Grespan R, BersaniAmado CA, Cuman RKN. Effects of Thymol and Carvacrol, Constituents of Thymus vulgaris $L$. Essential Oil, on the Inflammatory Response. Evid 
Based Compl Alt 2012; 2012, article ID 657026, 10 pages.

10. Manual de Utilização de Animais. CEUA-FIOCRUZ, 2008.

11. Silva-Comar FMS, Wiirzler LAM, Silva-Filho SE, Kummer $R$, Pedroso RB, Spironello RA, Silva EL, BersaniAmado CA, Cuman RKN. Effect os Estragole on Leukocyte Behavior and Phagocytic Activity of Macrophages Evid Based Compl Alt 2014; 2014, article ID 784689, 7 pp.

12. Vonapart A, Karioti A, Recio MC, Máñez S, Ríos JL, Skaltsa E, Giner RM. Effects of Terpenoids from Salvia willeana in Delayed-type Hypersensitivity, Human Lymphocyte Proliferation and Cytokine Production. Nat Prod Commun 2008; 3: 1953-1958.

13. Cassatella MA. The production of cytokines by polymorphonuclear neutrophils. Immunol Today 1995; 16: 21-26.

14. Ribeiro RV, Silva RM, Lima JCS, Martins DTO. Antiinflammatory, antinociceptive and antipyretic effects of hydroethanolic extract from Macrosiphonia velame (A. St.-Hil.) M. Arg. in animal models. Braz J Pharm Sci 2010; 46(3): 515-523.

15. Winterbourn CC, Kettle AJ. Biomarkers of myeloperoxidase-derived Hypochlorous acid. Free Radical Biol Med 2000; 29(5): 403-409.
16. Crume KP, Miller JH, La Flamme AC. Peloruside A, an antimitotic agent, specifically decreases tumor necrosis factor- $\alpha$ production by lipopolysaccharidestimulated murine macrophages. Exp Biol Med 2007; 232: 607-613.

17. Wright SD, Ramos RA, Tobias PS, Ulevitch RJ, Mathison JC. CD14, a receptor for complexes of lipopolysaccharide (LPS) and LPS binding protein. Science 1990; 249: 1431-1433.

18. Lorne E, Zhao X, Zmijewski JW, Liu G, Park YJ, Tsuruta $Y$, Abraham E. Participation of mammalian target of rapamycin complex 1 in toll-like receptor 2- and 4induced neutrophil activation and acute lung injury. Am J Respir Cell Mol Biol 2009; 41(2): 237-245.

19. Li ZF, Zhang $Y$, Gao J, Zhang PJ, Wang JX, Liu XG. Expression and significance of Toll-like receptor 4 of splenic macrophage in patients with hypersplenism due to portal hypertension. Zhonghua Yi Xue Za Zhi 2004; 84(13): 1088-1091.

20. Gayathri B, Manjula N, Vinaykumar KS, Lakshmi BS, Balakrishnan A. Pure compound from Boswellia serrata extract exhibits anti-inflammatory property in human PBMCs and mouse macrophages through inhibition of TNF- $\alpha, I L-1 \beta, N O$ and MAPkinases. Int Immunopharmacol 2007; 7: 473-482. 